\title{
Influence of Cracks on the Lifetime of Semi-Rigid Pavements
}

\author{
Krystyna Kazimierowicz-Frankowska \\ Institute of Hydro-Engineering, Polish Academy of Sciences, ul. Kościerska 7, 80-328 Gdańsk, Poland, \\ e-mail: krystyna@ibwpan.gda.pl
}

(Received September 15, 2016; revised January 06, 2017)

\begin{abstract}
This paper focuses on a better understanding of the process of reflective cracking propagation through the pavement structure. A series of finite element numerical simulations were conducted to investigate the initial stress and strain states in typical semi-rigid pavements with and without reflective cracks under traffic loading. It was assumed that reflective-cracks propagate from the base layer to the pavement surface. The influence of selected parameters, such as the load position, overlay thickness, and subgrade quality on stress and strain concentrations was investigated. The behaviour of the pavement structure under repeated traffic loading was analyzed in terms of ground compaction. The original theoretical model proposed by Prof. Andrzej Sawicki was used to predict the deformation of a pavement subgrade subjected to traffic loading. The damaging effect of cracks appearing in the pavement structure was investigated. It was found that even a single crack in the pavement structure may significantly reduce the pavement lifetime.
\end{abstract}

Key words: pavement deformations, traffic load, reflective cracks, ground compaction

\section{Introduction}

One of the most frequent failure modes of pavement structures is the appearance of cracks on their surface. Even initial hairline cracks may progress and cause a strong degradation of the road structure (resulting from water intrusion and reduction in soil bearing capacity). Depending on their nature, causes of initiation and direction of propagation, several types of cracks can be defined (Chen et al 2006). This paper focuses on a better understanding of the influence of cracks propagating bottom-up into the surface of a bituminous layer on the reduction in the pavement lifetime. This phenomenon, called reflection cracking, is mainly caused by traffic loading, temperature variations and uneven subgrade movements. It is one of the most important failure mechanisms in pavements which joins and cracks in their structure.

The main reasons leading to cracks being initiated at the bottom of the uncracked top layer and to their upward propagation have already been understood well enough for this phenomenon to be modelled (see, for example, Kazimierowicz-Frankowska 2008). The external wheel load results in high stress and strain levels in the layer 
above the existing crack. Discontinuity in pavements reduces the bending stiffness of the rehabilitated pavement section and creates a stress concentration. When conditions are such that the stress state exceeds the fracture resistance of the uncracked top layer, a mechanism of pavement deterioration caused by reflective cracks can be initiated, and the cracks can propagate (Kim and Buttlar 2002, Kazimierowicz-Frankowska 2009). Therefore, the resistance of the top pavement layer against cracks is very important for the pavement life span. Issues related to pavement design and factors affecting the propagation of reflective cracking have often been investigated in recent times (overviews and state-of-the-art reports on the problem can be found in the proceedings of the periodically organized RILEM Conferences on Reflective Cracking and Cracking in Pavements). To retard reflection cracking different design strategies are used (Tschegg et al 1998, Kim and Buttlar 2002, Zhou and Zheng 2002, Chen et al 2006, Khodaii et al 2008). Many modes of cracking have been described (Zeghal and Mohamed 2000, Kazimierowicz-Frankowska 2008) to simulate the behaviour of pavement structures under traffic loading.

In spite of extensive studies, current methods of pavement design are not successful. Cracks and joints in bottom pavement layers quickly propagate through bituminous layers (Martin-Perez and Mohamed 2000, Haas and Tighe 2000). In colder climates, such as the northern portion of the United States and Canada, reflective cracking often occurs in the overlay after the first or second winter following rehabilitation (Buttlar and Bozkurt 2000). Unfortunately, there are few design tools that can be applied to the problem, and there is no reliable method of predicting the accurate development of reflective cracking as a function of the traffic and main pavement and subgrade parameters (Perez et al 2007). Only very limited research has been done to investigate the effect of cracks in the pavement structure on pavement subsoil deformation under repeated traffic loads. This paper has been written to improve knowledge in the field. The first part of the article is devoted to comparing the stress and strain states in pavement structures with and without cracks under a single application of a wheel load. It is assumed that reflective-cracks propagate from the base layer to the pavement surface. The second part deals with the influence of reflective cracking in the pavement structure on subgrade deformation due to repeated traffic loads. The lifetime of pavements with and without cracks in their structure are compared. The main conclusions are presented.

\section{Formulation of the Problem}

\subsection{Objectives}

The analyses were conducted:

- to compare the maximum values of stresses and settlements in pavements with and without cracks; 
- to investigate the process of change in the critical stress and strain values in pavements during the propagation of cracks within the bituminous top layer;

- to recognize the influence of the wheel load position in relation to cracks on the critical stress and strains generated in the pavement structure;

- to compare the increase in maximum settlements of pavements with and without cracks due to ground compaction under an increased number of traffic loads;

- to investigate the effect of cracking on the pavement service life. The critical settlement of the pavement-subgrade system was set at $50 \mathrm{~mm}$. The number of cyclic traffic loadings resulting in the critical settlement was calculated for pavements with and without cracks. The damage factor of cracking was expressed as a decrease in the lifetime of a cracked pavement, compared to the lifetime of an uncracked pavement.

\subsection{Basic Principles}

The following general assumptions were made:

- the problem is considered under the plane strain conditions;

- thermal stresses are not taken into account; pavementñs parameters selected for calculations (see Table 1) are appropriate for the approximate of $+10^{\circ} \mathrm{C}$ and time of loading $0.02 \mathrm{~s}$; for this traffic-loading conditions FEM simulations were made;

- the pavement structure is modelled as a semi-infinite linear system consisting of three layers (the wearing course, the base course and the subgrade - compare Fig. 1), characterized by properties presented in Table 1 . Since the behaviour of the pavement structure under repeated traffic loading was analyzed in terms of ground compaction, a wide range of subgradeñs parameters was taken into account during the analysis. However, from practical point of view, the results presented for Young's modulus in the range between 50-100 MPa are the most important;

- each layer of the pavement structure is assumed to be continuous, uniform and isotropic;

- cohesionless ground is used as the subgrade of the pavement structure;

- the crack in the base layer is simulated as a $10 \mathrm{~mm}$ wide gap in the pavement structure, to be consistent with field surveys (Pais 1999);

- it is assumed that reflective cracks propagate directly upwards from the crack in base layer;

- traffic wheel-loading is simulated by applying a constant vertical pressure of $P=$ $700 \mathrm{kPa}$ distributed over a distance of $0.2 \mathrm{~m}$. The loading conditions were assumed following Martin-Perez and Mohamed 2000, Vanelstraete et al 2000 and Sobhan et al 2004.

- two different positions of loading in relation to the crack were considered: a vehicle wheel load applied directly above the existing crack in the pavement structure (symmetrical position) and a load applied asymmetrically with regard to the crack (asymmetrical position). They are presented in Figure 1. 
Table 1. Main parameters of pavement layers

\begin{tabular}{|l|c|c|c|}
\hline Material & Modulus $E(\mathrm{MPa})$ & Poisson's ratio & Thickness $(\mathrm{mm})$ \\
\hline bituminous layer & 10000 & 0.36 & 200 \\
\hline base layer & 6000 & 0.35 & 300 \\
\hline subgrade & $50-1000$ & 0.30 & 1500 \\
\hline
\end{tabular}

a)

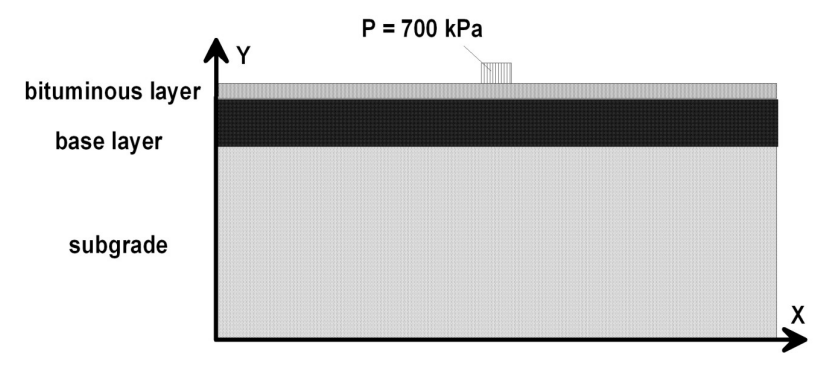

b)

c)
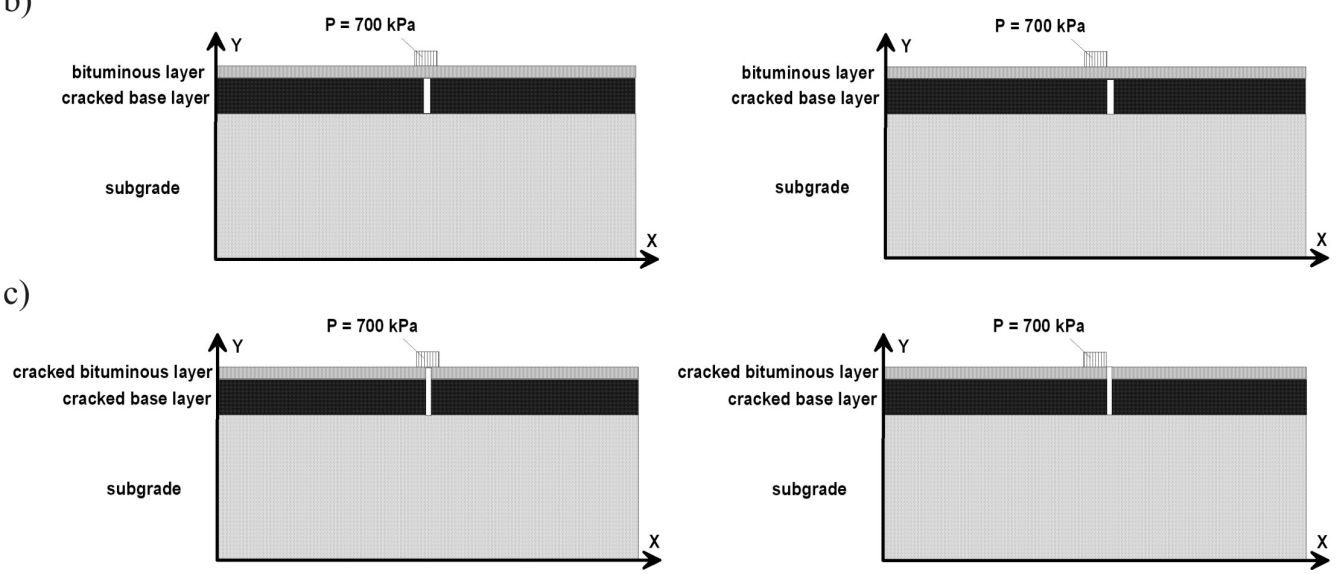

Fig. 1. Figure 1. Cross-section of the pavement structure: a) pavement without cracks; b) pavement with a crack in the base layer; c) pavement with a reflective crack in its structure

\subsection{Calculation Methodology}

The calculation procedure consisted of two main phases. First, the response of the pavement-subgrade system to a single vehicle wheel loading was analyzed by the finite element method (FEM). During this phase of calculations, the following assumptions were made:

- eight nodes of isoparametric rectangular elements were used for the finite element model. The finite element mesh was finest in the contact zone, where large stress and strain gradients were expected. A typical mesh used for the calculations is shown in Figure 2; 


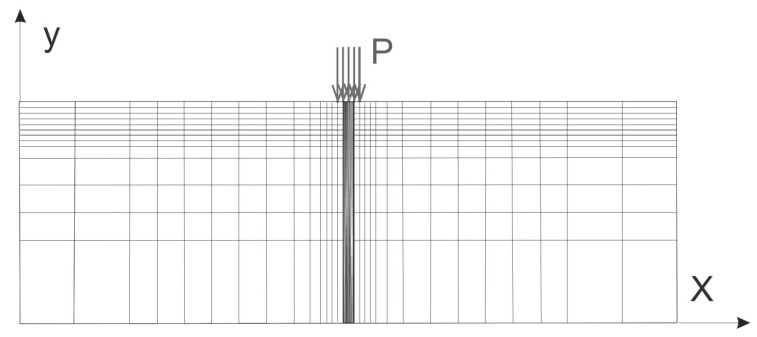

Fig. 2. A typical finite element mesh used for calculations

- conventional kinematic boundary conditions were adopted, i.e. a roller support on all four vertical boundaries of the mesh and a fixed support at the bottom of the mesh;

- pavement cracking progression was modelled by removing suitable finite elements from the base course (in the second phase of analysis) and the wearing layer (in the third phase). It was assumed that the reflective crack propagates upwards from the existing crack in the base course;

- a static vertical load was applied to the surface of finite elements to calculate the strain and stress fields caused by the wheel in a given position. The normal contact pressure was uniformly distributed over the contact area;

- the elements of the strain tensor $\left(E_{x}, E_{y}\right.$ and $\left.E_{x y}\right)$ corresponding to the maximum value of traffic loading were computed for each finite element.

In the second phase of calculations, the original soil compaction model (Sawicki 1987) was used to predict subgrade deformation beneath the pavement structure under cyclic traffic loading. This theoretical model, proposed by Prof. Sawicki, has been successfully applied to solve different engineering problems and has been confirmed in practice (Sawicki 1991). It is formulated in terms of cyclic stress and strain amplitudes. The author introduced the function of soil compaction $\Phi$, which is computed as an irreversible porosity change due to cyclic shearing. The following compaction law was formulated:

$$
\frac{d \Phi}{d N}=D_{1} J \exp \left(-D_{2} \Phi\right),
$$

where $N$ is the number of loading cycles applied, whereas $D_{1}$ and $D_{2}$ denote constants for a given soil, which describe the compaction properties of the subgrade soil and are determined experimentally. The quantity $J$ in Equation (1), is defined as the second invariant of the strain amplitude deviator. It is computed from the following formula:

$$
J=\frac{1}{3}\left[\left(E_{x}-E_{y}\right)^{2}+E_{x} E_{y}\right]+E_{x y}^{2},
$$

where $E_{x}, E_{y}$ and $E_{x y}$ denote elements of the strain tensor, which were determined in the previous phase of calculations; $X$ corresponds to the horizontal direction, $Y$ to 
the vertical direction, and $X Y$ to the shear component of strains. The strain amplitude deviator $J$ should be computed in each finite element (for the maximum values of strains in the subgrade due to traffic). It is assumed that it is constant in each finite element. Then, the compaction $\Phi$ should be calculated in each finite element. Once the compaction $\Phi$ has been determined, the settlement $S$ of each finite element column can be computed by the following formula:

$$
S=\frac{n_{0}}{1-n_{0}} \int_{h_{1}+h_{2}}^{h_{1}+h_{2}+h_{3}} \Phi d y,
$$

where $n_{0}$ is the initial porosity of the soil, and $h_{1}, h_{2}, h_{3}$ denote the thickness of the bituminous, base, and subgrade layers, respectively.

A simple computer program written by the author of the article was used to analyze typical pavement settlements under repeated traffic loading. Calculations were performed for a cohesionless subsoil ("Lubiatowo" sand), characterized by compaction parameters presented in Table 2 . They were determined experimentally in the Geomechanics Laboratory of the Institute of Hydro-Engineering. Dense soil characteristics were used as input data for series of basic numerical calculations.

Table 2. Basic compaction parameters of the subgrade soil

\begin{tabular}{|c|c|c|c|c|c|}
\hline Initial density & Relative density & Maximum void ratio & Minimum void ratio & $D_{1}$ & $D_{2}$ \\
\hline Dense & 0.86 & 0.84 & 0.52 & 4.87 & 0.19 \\
\hline
\end{tabular}

\section{Results of Analysis}

\subsection{Scope of Analyses}

The parametric analyses of the external wheel load cases involved the following design parameters: the magnitude and position of wheel loading, the thickness of the bituminous layer, and the quality of the subgrade. The "base" case for comparative analyses was defined as a pavement section characterized by following parameters:

- bituminous layer: thickness of $0.2 \mathrm{~m}$; elastic modulus of $10000 \mathrm{MPa}$;

- base layer: elastic modulus of $6000 \mathrm{MPa}$;

- subgrade: elastic modulus of $100 \mathrm{MPa}$.

A wheel load of $700 \mathrm{kPa}$ distributed over a distance of $200 \mathrm{~mm}$ was assumed in this case. It was also assumed that a $10 \mathrm{~mm}$ wide crack propagates through the base and bituminous layers of the pavement structure. 


\subsection{Initial Stress and Strain States in the Pavement}

To investigate the effects of axle load and tire pressure on the behaviour of the three-layer system shown in Figure 1, series of numerical analyses were conducted, assuming the value of the loading pressure $P=700 \mathrm{kPa}$ and the elastic modulus of the three layers given in Table 1 . The main results of the analyses are summarized in Figures 3-6.

a)

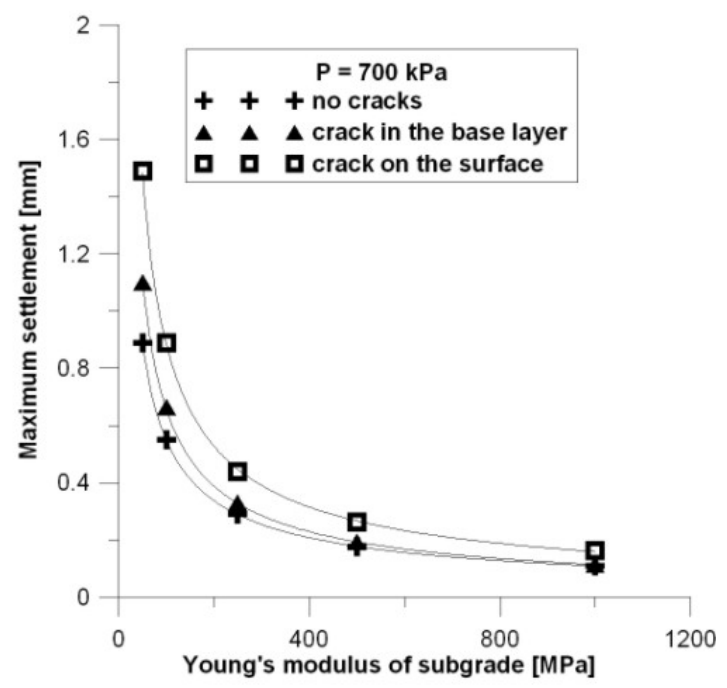

b)

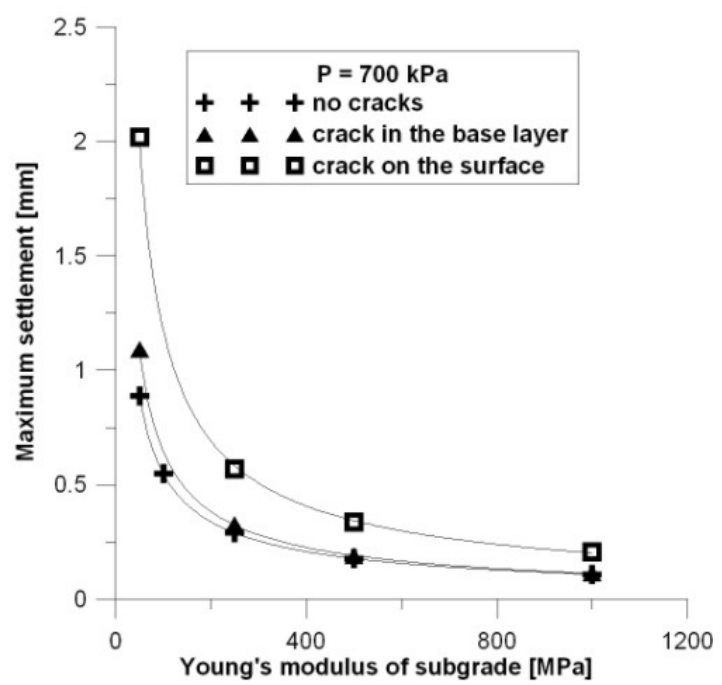

Fig. 3. Variation in maximum pavement settlements with Young's modulus of the subgrade: a) load applied symmetrically above the crack; b) load applied asymmetrically with regard to the crack 
They show typical stress and strain responses of the pavement system to traffic loading impact. Figure 3 presents the variation in the maximum pavement settlements with changing Young's modulus of the subgrade. It was plotted for two different positions of traffic loading in relation to the crack in the pavement structure. Figure 3 illustrates the variation in maximum pavement settlements during three selected phases of pavement working (uncracked pavement, pavement with a crack in the base layer and pavement with a crack on the surface).

It is clearly seen that the crack in the pavement system significantly increases permanent deformations due to traffic. Deformations generated at the surface of the pavement with reflective cracks in the bituminous layer can be nearly twice the size of those for the uncracked sections. The difference between the maximum pavement settlements obtained for uncracked pavement systems and for systems with a crack in the base layer is rather insignificant (only a few percent). Figure 3 also shows the significant impact of the load position in relation to the crack on maximum pavement settlements due to traffic. Greater settlements were obtained for the load applied asymmetrically with regard to crack.

Calculations were performed for Young's modulus of the subgrade varying in the range between $50 \mathrm{MPa}$ and $1000 \mathrm{MPa}$. A very sharp increase in pavement settlements was observed for the cases most important from practical point of view (when Young's modulus of the subgrade decreased to below $250 \mathrm{MPa}$ ). The same trend was noted for the three phases of pavement deterioration analyzed. The numerical results confirm the well-known fact that pavements laid on stronger subgrades are more resistant to displacements.
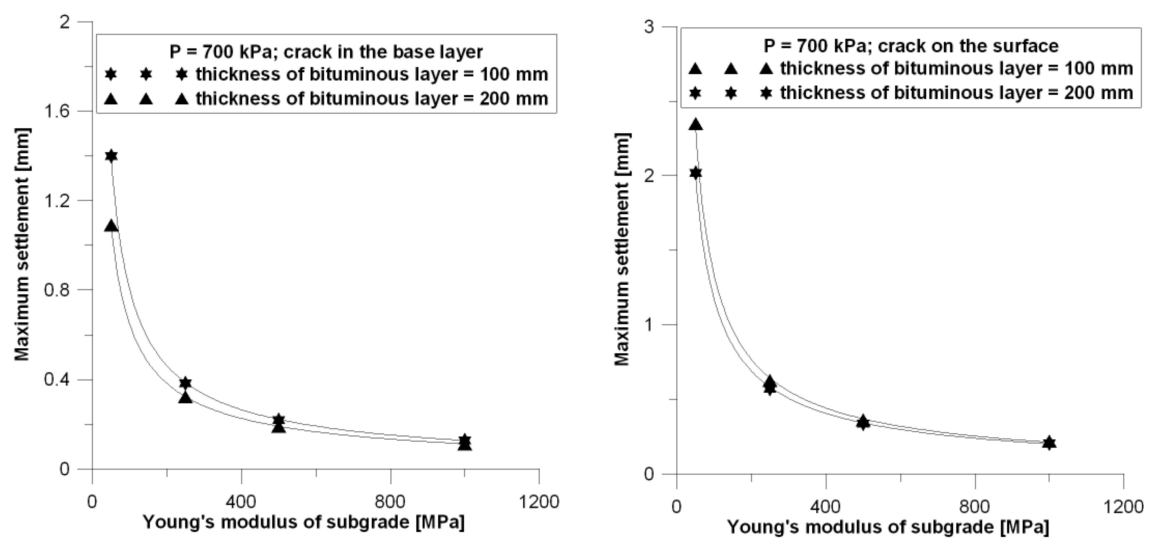

Fig. 4. Influence of the thickness of the bituminous layer on maximum pavement settlements. Load applied asymmetrically with regard to the crack

A comparison of the maximum pavement settlements for two different thicknesses of the bituminous layer is shown in Figure 4. As can be expected, an increase in pavement deformations was observed in the case of the thinner bituminous layer. The 

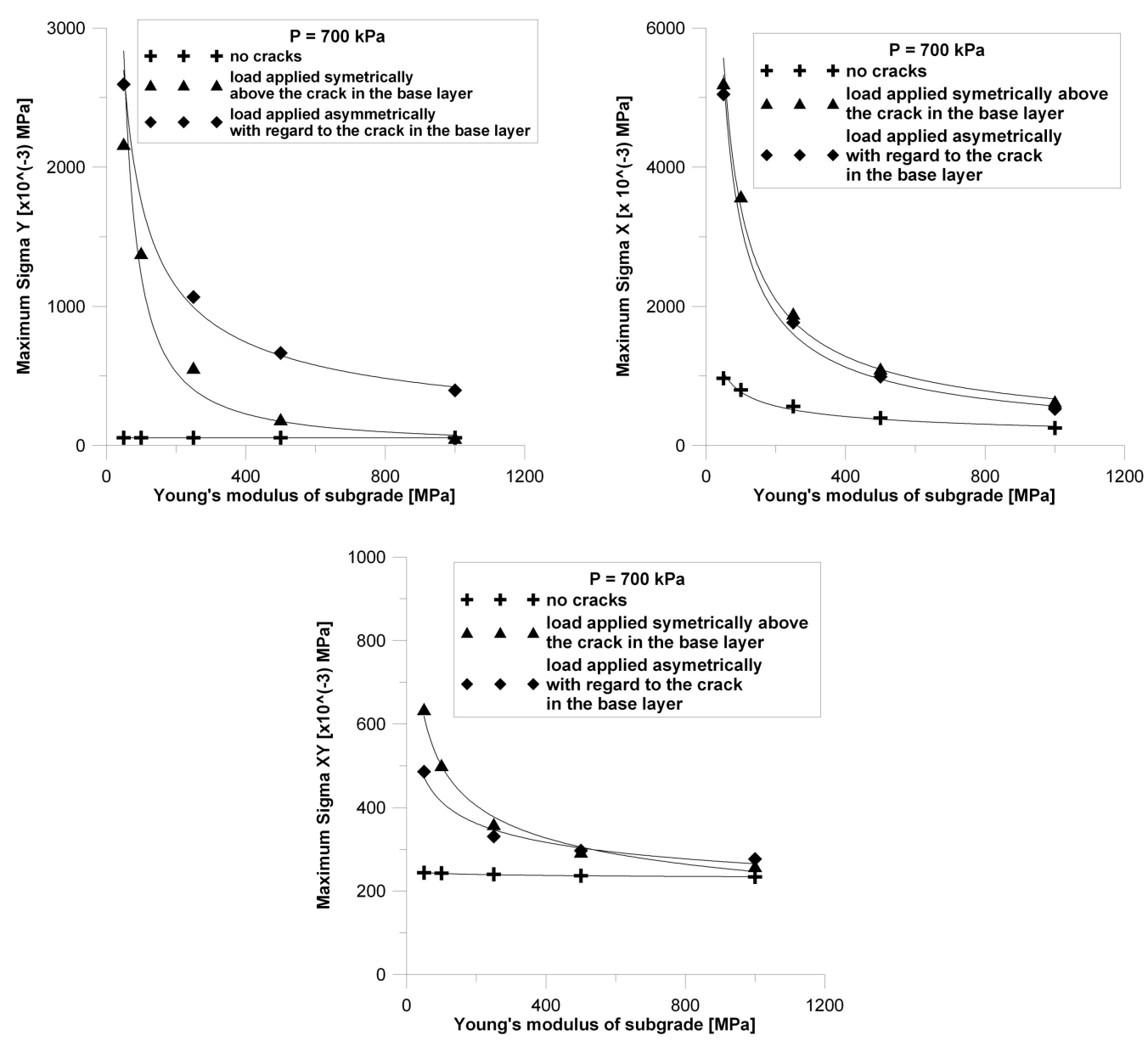

Fig. 5. Comparison of maximum tensile stresses in uncracked pavements and in pavements with cracks in the base layer. Two different load positions

difference is relatively insignificant for Young's modulus of the subgrade above 200 $\mathrm{MPa}$ (only a few percent) but increases to approximately $20 \%$ for the pavement section constructed over a subgrade characterized by Young's modulus of $50 \mathrm{MPa}$.

Figure 5 shows the maximum tensile stresses in the pavement system that develop when a vehicle travels over pavement layers as a function of the stiffness of the subgrade layer. The maximum stresses in the $\mathrm{X}, \mathrm{Y}$ directions and the shear stresses are compared. It is easy to note that stresses in uncracked and cracked pavements differ considerably. A very high tensile stress occurs at the bottom of the bituminous layer, directly above the existing crack.

The effect of the wheel loading position was also examined. Two critical positions of traffic loading in relation to the crack were investigated (a vehicle wheel load directly above the crack in the pavement structure and a load positioned asymmetrically with regard to the crack, i.e. adjacent to the existing crack). Figure 5 illustrates 
the influence of the load position in relation to the crack on the stress state. It may generally be concluded that the changing load position influences only the values of stresses induced in the $\mathrm{Y}$ direction. Greater values of tensile stresses were obtained for the asymmetrical position of loading with regard to the crack. The same qualitative character of results was observed for different traffic loading pressures. Their quantitative character was affected by the wheel loading pressure.
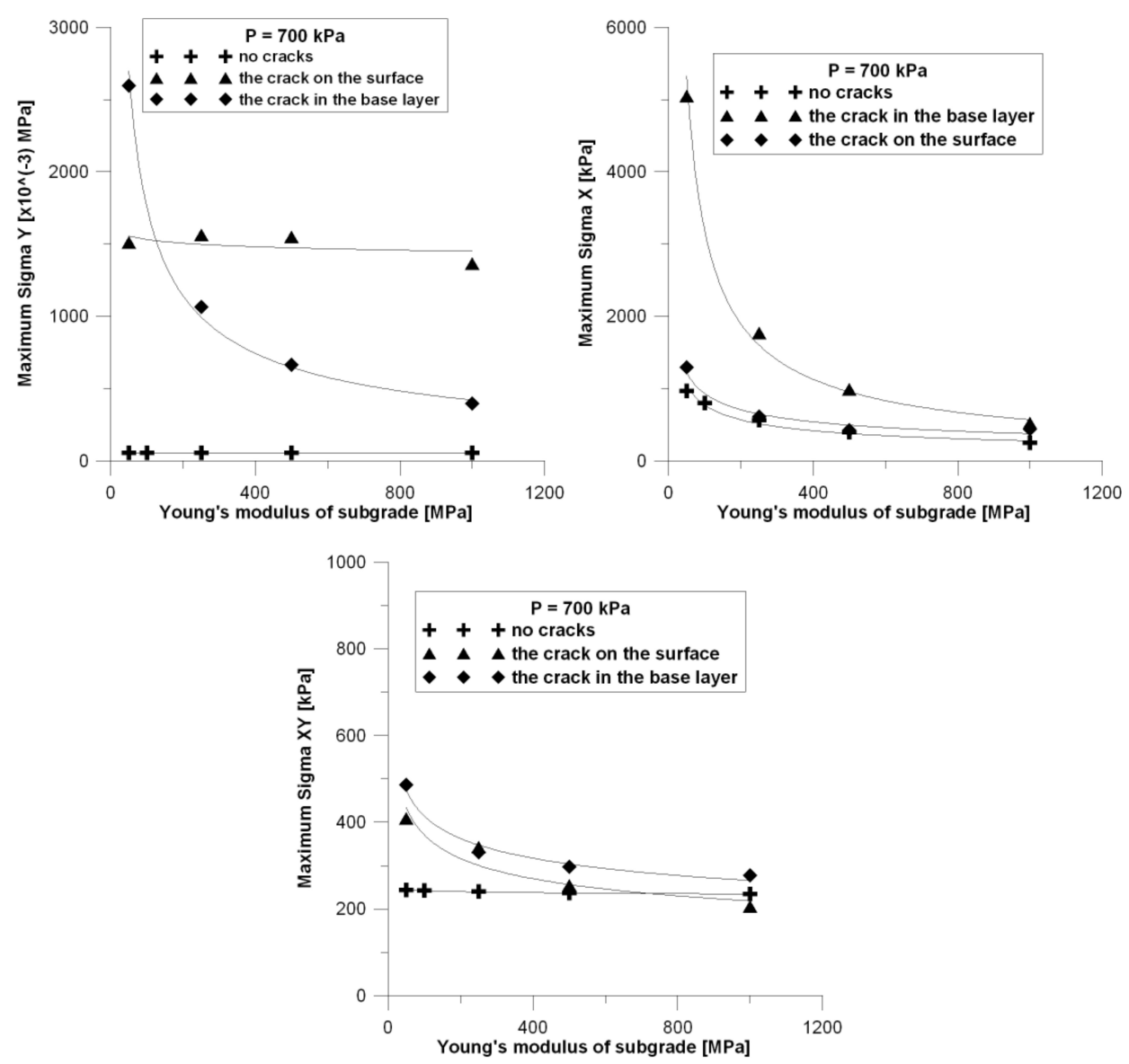

Fig. 6. Variation in stresses with the subgrade modulus. Comparison of maximum tensile stresses in pavements during three phases of working. Load applied asymmetrically with regard to the crack

Changes in maximum tensile stresses during the propagation of the crack through the pavement structure are presented in Figure 6. It was plotted for a load applied asymmetrically with regard to the crack. The impact of the subgrade modulus on pavement behaviour under traffic load is clearly visible. The difference between results obtained for cracked and uncracked pavements increases with the decreasing subgrade modulus. 


\subsection{Compaction of the Pavement Subgrade under Repeated Traffic Loading}

\section{Influence of subgrade properties}

In the first step, the impact of the subgrade modulus on maximum settlements of the pavement under repeated traffic loading was investigated. Fig. 7 shows a comparison of the maximum settlements obtained for pavements placed on subgrades characterized by different properties.
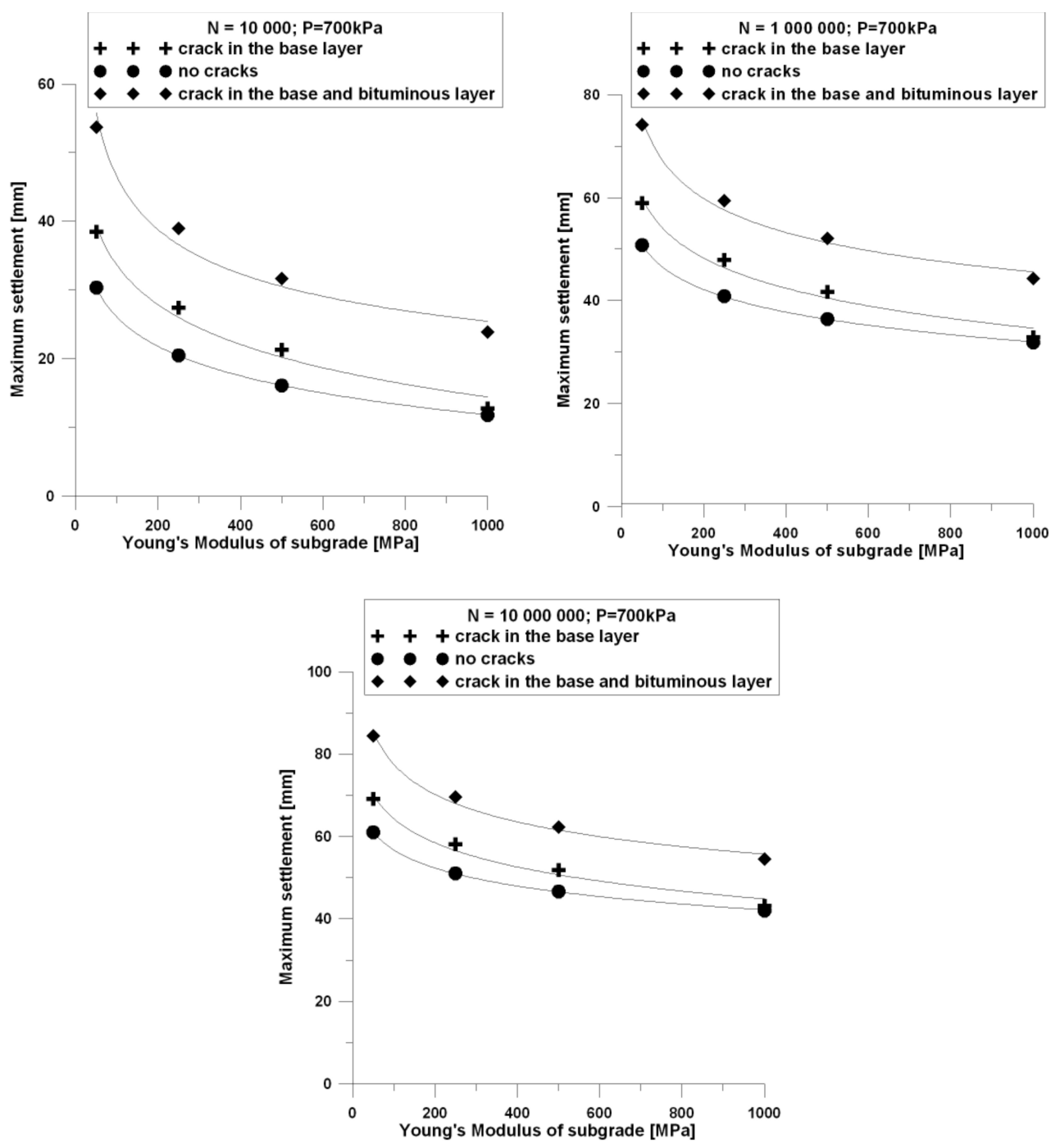

Fig. 7a. Variation in maximum pavement settlements with the subgrade modulus. Comparison of pavement behaviour during three phases of deterioration: $P=700 \mathrm{kPa}$. Load applied asymmetrically with regard to the crack. 

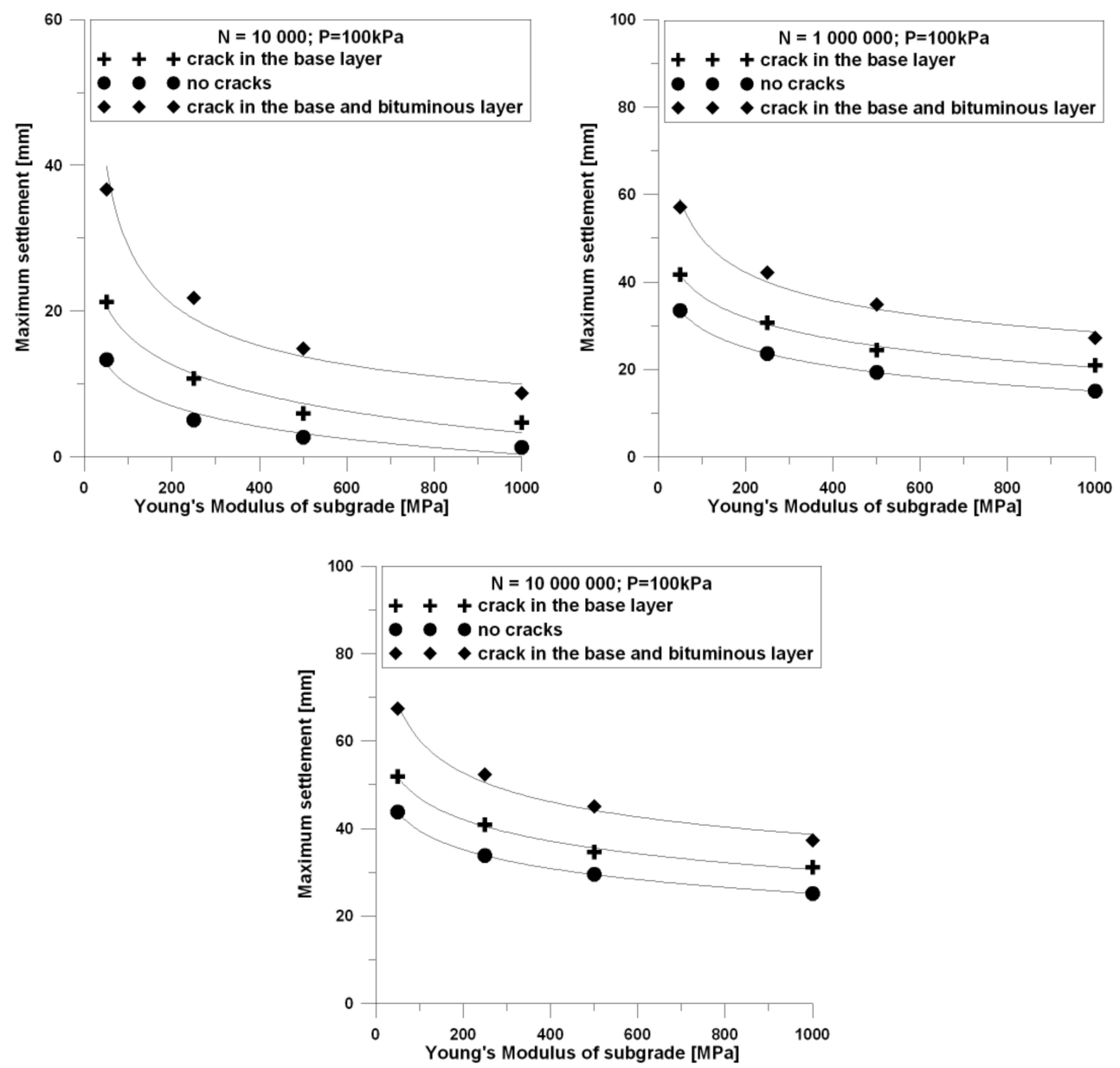

Fig. 7b. Variation in maximum pavement settlements with the subgrade modulus. Comparison of pavement behaviour during three phases of deterioration: $P=100 \mathrm{kPa}$. Load applied asymmetrically with regard to the crack.

Numerical simulations were performed for three selected phases of pavement deterioration (pavement without cracks, pavement with a crack in base layer and pavement with a reflective crack) and for different numbers of load applications in the range between 10000 and 10000 000. It is clearly seen that the maximum values of displacements obtained for a cracked pavement built on weak subgrades (characterized by $E=50 \mathrm{MPa}$ ) are nearly twice as high as deformations predicted for uncracked structures after 10000 cycles of traffic loading. The difference between displacement values decreases with increasing number of load applications. Maximum settlements obtained for the pavement with a reflective crack are approximately $32 \%$ higher than those predicted for uncracked pavement after 10000000 applications of traffic loading. 


\section{Influence of traffic load pressure}

Calculations were performed for two different pressures of traffic loading: $P=$ $700 \mathrm{kPa}$ and $P=100 \mathrm{kPa}$. The second one is smaller than usually applied in practice, but it was used only for comparison purposes.

Typical results obtained for these two cases are presented in Fig. 7. The curves, which show the relationship between maximum displacements and the stiffness of the subgrade layer have the same qualitative character. Their quantitative character is affected by the magnitude of traffic loading.

\section{Influence of the traffic load position in relation to the crack}

To investigate the effect of the traffic load position on pavement settlements, two critical positions of loading in relation to the crack were considered (they are defined in Section 2.2 and in Fig. 1). Fig. 8 presents a comparison of maximum settlements obtained for the symmetrical and asymmetrical positions of loading with regard to the crack in the second phase of pavement deterioration (a crack in the base layer). It is easy to note that the difference between vertical displacements predicted for the two cases is relatively insignificant.

For a pavement with a reflective crack in its structure the results of the analysis are quite different. The relationship between computed maximum vertical displacements in the pavement structure and the position of loading with regard to the crack in the third phase of road working is presented in Fig. 9. It is clearly seen that the displacements were greater when the load was applied asymmetrically with regard to the crack. The difference between vertical displacements predicted for the two cases is clearly visible.

\section{Influence of the thickness of the bituminous layer}

Calculations were performed for two different thicknesses of the bituminous layer: 100 and $200 \mathrm{~mm}$. The influence of this parameter on pavement settlements is shown in Fig. 10. Numerical results confirm the well-known fact that, for a pavement with a crack in the base layer only, greater displacements appear when the bituminous layer is thinner. It is interesting to note that the influence of the bituminous layer thickness (in the investigated range) on pavement settlements is negligible in the third phase of deterioration (pavement with a reflective crack on the surface). In this case, nearly identical values of maximum vertical displacements were obtained for both thicknesses of the bituminous layer.

\subsection{The Damaging Effect of a Crack in the Pavement}

At the end of the investigation, the damaging effect of cracking in the pavement was summarized. A comparison of the predicted service life of pavements with and without cracks is presented in Table 3. The critical settlement of the pavement-subgrade system was set at $50 \mathrm{~mm}$. The number of cyclic traffic loadings resulting in the critical 

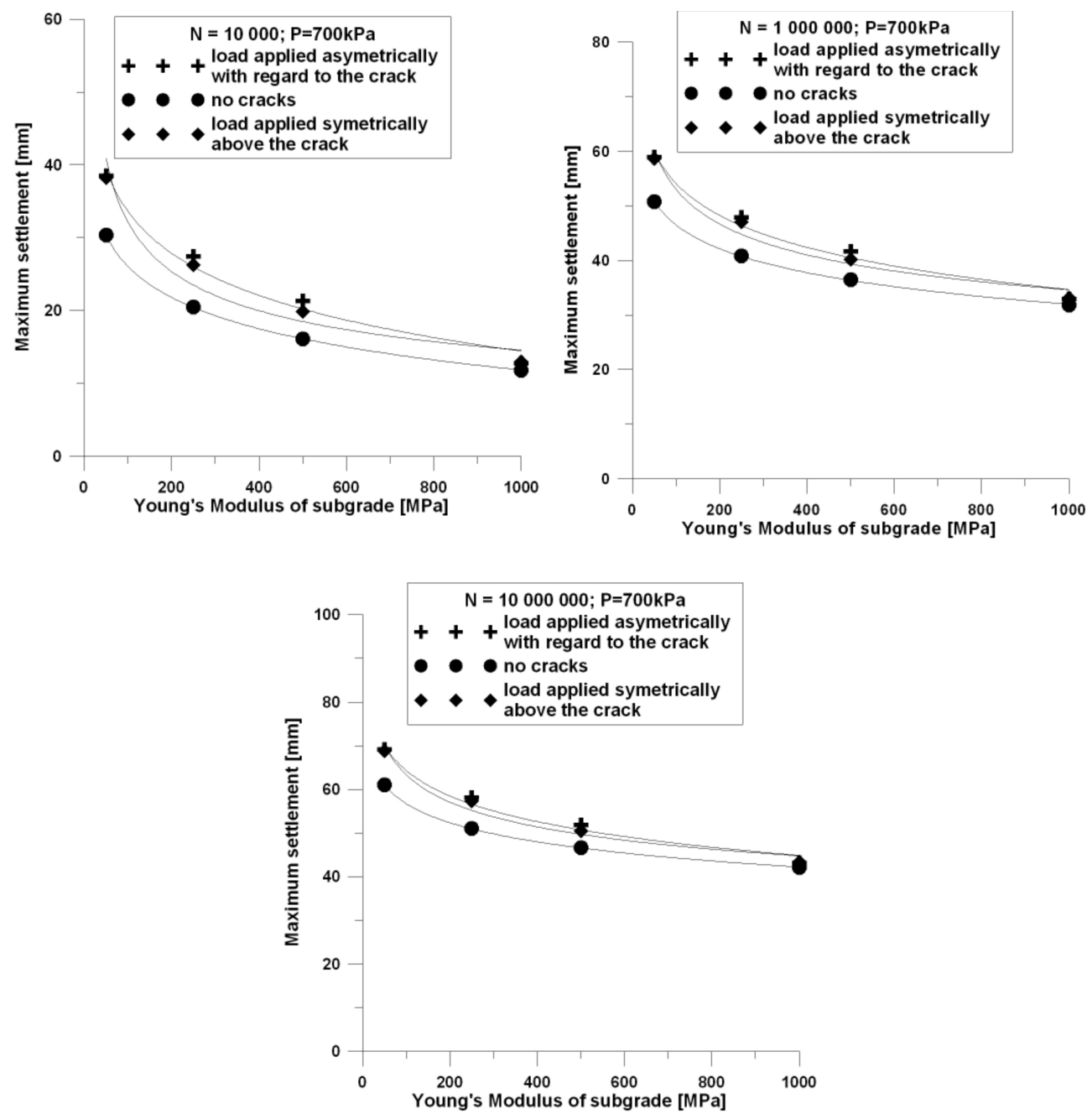

Fig. 8. Influence of the load position in relation to the crack on variation in pavement settlements. Comparison of maximum pavement settlements in pavements with cracks in the base layer

settlement was investigated. The relationship between the number of traffic load repetitions $N_{\text {uncrack }}$ (in the pavement without a crack) and $N_{\text {crack }}$ (in the pavement with a crack) needed for the critical pavement settlement to appear is defined as the lifetime gain $(L G)$ :

$$
L G=\frac{N_{\text {uncrack }}}{N_{\text {crack }}} .
$$

It is clearly seen that the appearance of a crack in the pavement structure significantly reduces the pavement service lifetime. Table 3 summarized the influence of 

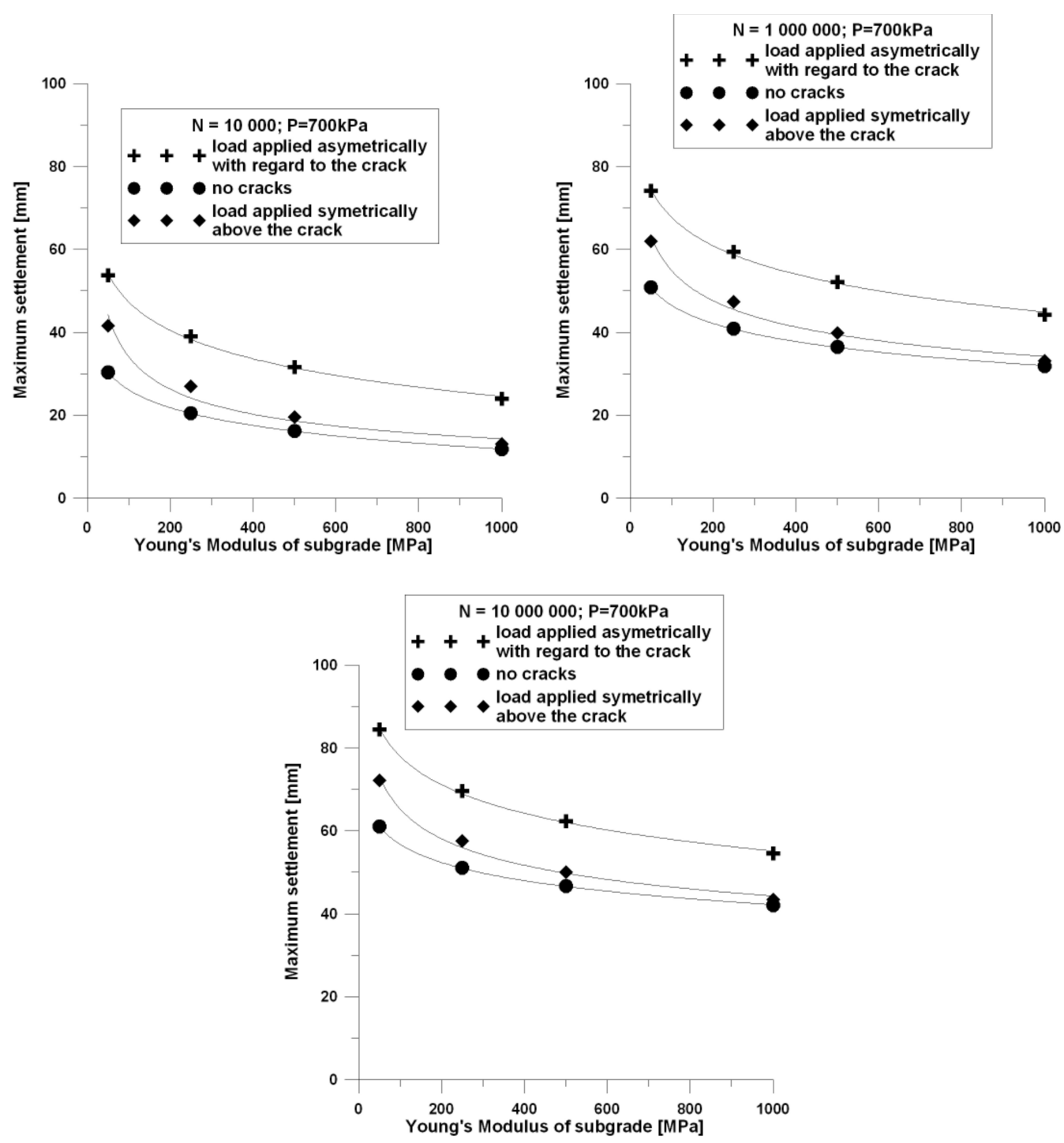

Fig. 9. Influence of the load position in relation to the crack on variation in pavement settlements. Comparison of maximum pavement settlements in pavements with cracks in the base and bituminous layers

such parameters as the modulus of the subgrade layer, the pressure of traffic loading, the load position in relation to the crack, and the thickness of the bituminous layer on the settlements of a pavement subjected to traffic loading. The results of calculations show the negative effect of crack propagation on the road service lifetime. They also indicate that the damaging effect of cracking is especially important when the pavement has been laid on a soft subgrade. 

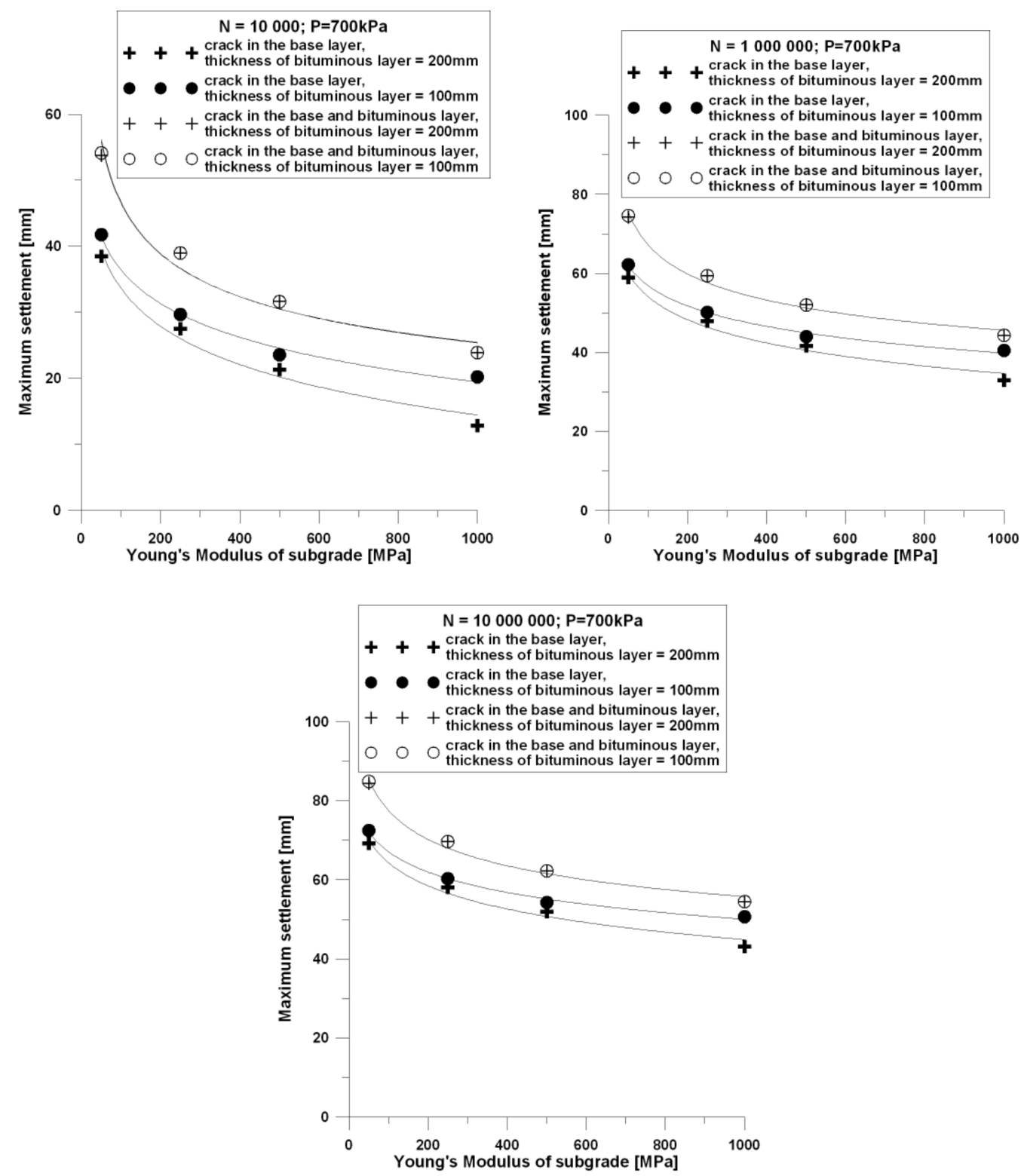

Fig. 10. Variation in maximum pavement settlements with the subgrade modulus. Influence of the thickness of the bituminous layer on settlements

\section{Conclusions}

An accurate prediction of reflective cracking propagation through the pavement structure is one of the most complicated tasks in pavement design. The main purpose of this paper was to better understand the behaviour of a typical pavement structure during reflective cracking propagation. Special attention was paid to the analyses of stress and 
Table 3. The damaging effect of a crack in the pavement

a) Comparison of pavement lifetimes predicted for three phases of pavement working (the "base case" of the pavement structure)

\begin{tabular}{|c|c|c|c|c|c|}
\hline $\begin{array}{c}\text { Young's modulus } \\
\text { of Subgrade } \\
{[\mathrm{MPa}]}\end{array}$ & $N_{\text {uncrack }}$ & $\begin{array}{c}N_{\text {crack base }} \\
\text { (crack in the } \\
\text { base layer) }\end{array}$ & $\begin{array}{c}N_{\text {crack reflective }} \\
\text { (crack in the base and } \\
\text { bituminous base) }\end{array}$ & $L G_{21}=\frac{N_{\text {uncrack }}}{N_{\text {crack base }}}$ & $L G_{31}=\frac{N_{\text {uncrack }}}{N_{\text {crack reflective }}}$ \\
\hline 50 & 840000 & 134000 & 4300 & 6.3 & 195.3 \\
\hline 250 & 7900000 & 1620000 & 121000 & 4.9 & 65.3 \\
\hline
\end{tabular}

b) Comparison of pavement lifetimes for two different thicknesses of the bituminous layer

\begin{tabular}{|c|c|c|c|c|}
\hline $\begin{array}{c}\text { Young's modulus } \\
\text { of Subgrade } \\
\text { [MPa] }\end{array}$ & $\begin{array}{l}N_{\text {crack base }} \\
\text { (crack in the base } \\
\text { layer), thickness of } \\
\text { bituminous layer } \\
=100 \mathrm{~mm}\end{array}$ & $\begin{array}{c}N_{\text {crack reflective }} \\
\text { (crack in the base and } \\
\text { bituminous layers), } \\
\text { thickness of bituminous } \\
\text { layer }=100 \mathrm{~mm}\end{array}$ & $\begin{array}{c}L G_{22}= \\
=\frac{N_{\text {crack base } 200 \mathrm{~mm}}}{N_{\text {crack base, }, 100 \mathrm{~mm}}}\end{array}$ & $\begin{array}{c}L G_{32}= \\
=\frac{N_{\text {crack reflective, } 200 \mathrm{~mm}}}{N_{\text {crack }} \text { reflective, } 100 \mathrm{~mm}}\end{array}$ \\
\hline 50 & 68800 & 3600 & 1.9 & 1.2 \\
\hline 250 & 975000 & 120500 & 1.7 & 1.0 \\
\hline
\end{tabular}

strain states under traffic loading. The behaviour of the pavement-subgrade structure was analysed in terms of ground compaction, using the theoretical model proposed by Prof. Sawicki. The main conclusions from the investigations are as follows:

- compaction of the subgrade under traffic loading may be one of the causes of pavement deformation;

- compaction occurs mainly in the top layer of the subgrade adjacent to the pavement. The depth of this layer is approximately $0.6-1.2 \mathrm{~m}$;

- even one crack in the pavement structure may significantly reduce the pavement service lifetime. Numerical results confirm the damaging effect of cracks propagating from the base layer towards the top bituminous layer;

- the position of the load in relation to the crack in the pavement structure strongly influences stress and strain states in the pavement.

Although the present results of finite element numerical analyses are far from exhaustive, they improve the knowledge of the influence of selected factors on the mechanism of crack initiation and propagation through a road structure.

\section{References}

Buttlar W. G., Bozkurt D. (2000) Cost-effectiveness of paving fabrics used to control reflective cracking, Transportation Research Record, Transportation Research Board, 1730, 139-149.

Chen D. H., Scullion T., Bilyeu J. (2006) Lessons learned on jointed concrete pavement rehabilitation strategies in Texas, Journal of Transportation Engineering, 132 (3), 257-265.

Haas R., Tighe S. (2000) Economic benefits of reducing and treating reflection cracking, Proceedings of the Fourth International RILEM Conference on Reflective Cracking in Pavements. Research in Practice, 495-505.

Kazimierowicz-Frankowska K. (2008) Comparison of stresses and strain states in pavements with and without reflective cracks, Journal of Transportation Engineering, 134 (11), 483-493. 
Kazimierowicz-Frankowska K. (2009) Pavement settlements due to subgrade compaction, Geotechnics and environmental problems with cohesive subgrades, E. Dembicki, M. Kumor, Z. Lechowicz (eds), University of Technology and Life Sciences in Bydgoszcz, 531-537.

Khodaii A., Fallah S., Nejad F. M. (2008) Effect of geosynthetics on reduction of reflective cracking in asphalt overlays, Geotextiles and Geomembranes, 27 (1), 1-8.

Kim J., Buttlar W. G. (2002) Analysis of reflective crack control system involving reinforcing grid over base-isolating interlayer mixture, Journal of Transportation Engineering, 128 (4), 375-384.

Martin-Perez B., Mohamed E. H. (2000) Determining the potential for reflection of cracks, Proceedings of Forth International RILEM Conference on Reflective Cracking in Pavements, 115-124.

Pais J. P. (1999) The reflective cracking in flexible pavement overlay design, Ph.D. thesis, Univ. of Minho, Minho, Portugal.

Perez S. A., Balay J. M., Tamagny P., Petit Ch. (2007) Accelerated pavement testing and modeling of reflective cracking in pavements, Engineering Failure Analysis, 14, 1526-1537.

Proceedings of the First International RILEM Conference on Reflective Cracking in Pavements (1989).

Proceedings of the Second International RILEM Conference on Reflective Cracking in Pavements (1993).

Proceedings of the Third International RILEM Conference on Reflective Cracking in Pavements (1996).

Proceedings of the Fourth International RILEM Conference on Reflective Cracking in Pavements. Research in Practice (2000) Ottawa, Ontario, Canada .

Sawicki A. (1987) An engineering model for compaction of sand under cyclic loading, Engineering Transactions, 35 (4), 677-693.

Sawicki A. (1991) Soil Mechanics for Cyclic Loadings, IBW PAN, p. 193.

Sobhan K., Crooks T., Tandon V., Mattingly S. (2004) Laboratory simulation of the growth and propagation of reflection cracks in geogrid reinforced asphalt overlays, Proceedings of Fifth International RILEM Conference on Cracking in Pavements. Mitigation, Risk Assesssment and Prevention, Limoges, France, 589-596.

Tschegg E. K., Ehart R. J. A., Ingruber M. M. (1998) Fracture behavior of geosynthetic interlayers in road pavements, Journal of Transportation Engineering, 124 (5), 457-464.

Vanelstraete A., Leonard D., Veys J. (2000) Structural design of roads with steel reinforcing nettings, Proceedings of the Fourth International RILEM Conference on Reflective Cracking in Pavements. Research in Practice, Ottawa, Ontario, Canada, 57-67.

Zeghal, Mohamed (2000) The role of unbound aggregate layers in reflective cracking, Proceedings of the Fourth International RILEM Conference on Reflective Cracking in Pavements. Research in Practice, Ottawa, Ontario, Canada, 103-113.

Zhou Z.-G., Zheng J.-L. (2002) The effect of geosynthetics materials in preventing asphalt pavements from reflective cracking, Proceedings of the Seventh International Conference on Geosynthetics, Balkema Publisher, 963-966. 